\title{
Strain in the ice sheet deduced from the crystal- orientation fabrics from bare icefields adjacent to the Sør-Rondane Mountains, Dronning Maud Land, East Antarctica
}

\author{
S. Fujita AND S. MAE \\ Department of Applied Physics, Faculty of Engineering, Hokkaido University, Sapporo 060, Japan
}

\begin{abstract}
Structural analyses of ice collected from the bare ice surface in the region of the Sør-Rondane Mountains were carried out. Crystal-orientation fabrics and the disposition of surface cracks were investigated to determine the stress/strain configuration in the ice sheet near the mountains. Single-maximum fabric patterns with the axis of the maximum roughly perpendicular to the flow line on the horizontal plane were observed. It was deduced from the observations that the ice exhibits a fabric pattern indicating that the ice sheet is subjected to vertical shear strain between the ice flow and the nunataks.
\end{abstract}

\section{INTRODUCTION}

Ice fabrics in polar ice sheets reveal deformational history of the ice (e.g. Azuma and Higashi, 1985; Fujita and others, 1987) and control the viscosity of the ice during further deformation (e.g. Azuma and Mae, 1988; Shoji and Langway, 1988; Jacka and Budd, 1989). Therefore, ice fabric is an important property to describe the dynamical behaviour of the ice sheet.
Ice fabric was analyzed in samples collected in the bare icefields surrounding the Sør-Rondane Mountains $\left(71-73^{\circ} \mathrm{S}, 21-29^{\circ} \mathrm{E}\right)$, Dronning Maud Land, East Antarctica (Fig. 1). The aim was to investigate the effect of the mountains protruding through the Antarctic ice sheet on the flow of the ice sheet around them. Ice fabrics of the samples and the disposition of cracks formed in the ice sheet were analyzed, considering the geographical location of the sites and orientation of the samples at those

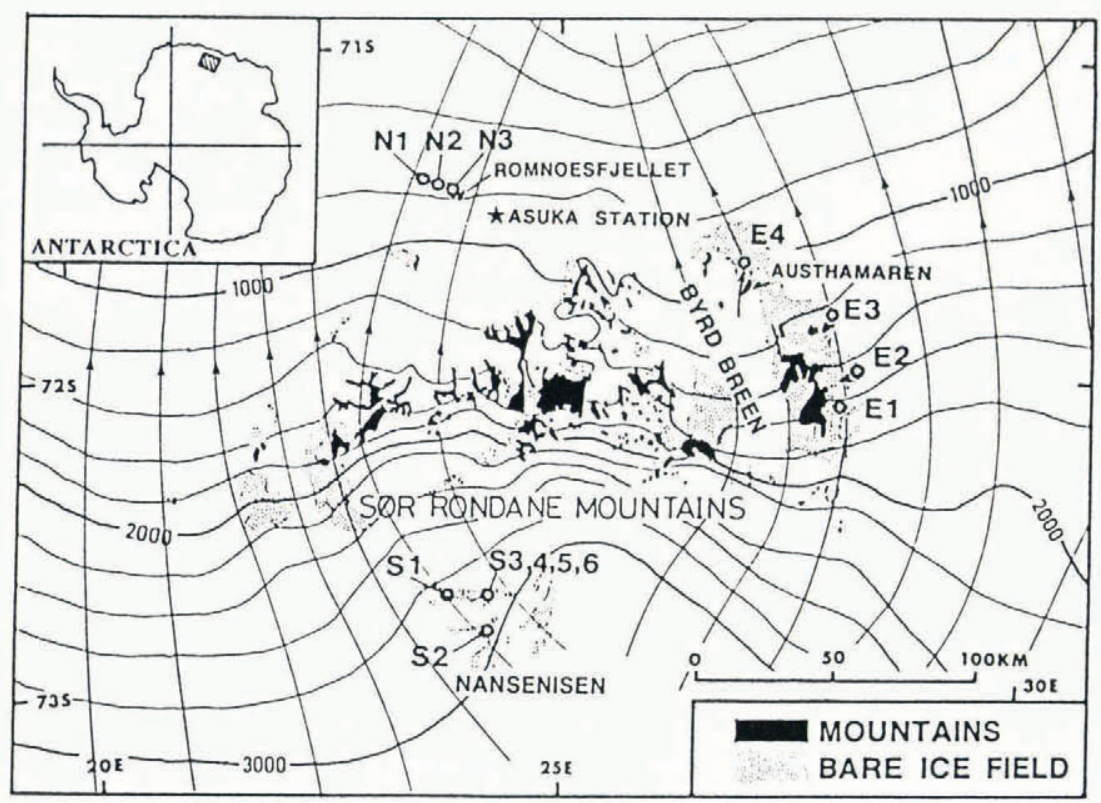

Fig. 1. Map of the ice sheet in the region of the Ser-Rondane Mountains, redrawn from a 1:2500000 map (east Dronning Maud Land-Enderby Land) edited by National Institute of Polar Research, Japan, in 1988. Ice samples were collected from bare-ice surfaces at sites denoted by E1, E2, E3 and E4, east of the mountains and at sites denoted by N1, $\mathcal{N} 2$ and $\mathcal{N} 3$, north of the mountains. Schematic flowlines are drawn perpendicular to the contour lines. 
sites. The stress/strain configuration was deduced from observations on the fabrics and cracks.

Ice samples used in the study were collected by the 29th Japanese Antarctic Research Expedition (JARE-29) in 1988 and 1989 (Naraoka and others, 1990) during a meteorite search in the bare icefields around the SørRondane Mountains. The investigations were carried out on ice samples at sites adjacent to the mountains with respect to the ice-flow direction and at sites up-stream of the mountains (Fig. 1). This paper reports specifically on the results of the study adjacent to the mountains. The results of structural analysis of ice upstream of the SørRondane Mountains, where more than 2000 specimens of meteorites were found (Naraoka and others, 1990), will be published elsewhere.

\section{ICE SAMPLES AND SAMPLING SITES}

Around the Sør-Rondane Mountains, ice samples were collected at sites E1, E2, E3 and E4 on the eastern side of and adjacent to the mountains and at N1, N2 and N3 in the northern, downstream area of the mountains as shown in Figure 1. All sites were located in bare icefields. Most samples were collected as ice blocks using a chain saw, while identifying geographical orientation. With this procedure, it was possible to analyze the ice samples for orientation and the stress/strain configuration in the ice sheet. Most ice samples were cut from about $0.5 \mathrm{~m}$ depth. For site E1, a $15 \mathrm{~m}$ core collected by JARE-24 in 1983, structural analysis was also carried out to compare the deeper ice with shallow ice.

Around sites E1, E2, E3 and E4, the ice sheet flows roughly from south-southeast to north-northwest. This has been deduced from the direction of the maximum surface slope, surveyed at each sampling site. Ice samples were collected to investigate the ice fabric in the area adjacent to the mountains with respect to the flowline direction. Among these sites, E1, E2 and E3 are on the eastern side of the nunataks but $\mathrm{E} 4$ is in the drainage basin west of the nunatak called Austhamaren (Fig. 1). A small arrow west of Austhamaren in Figure 1 shows the schematic flowline near site E4. In the northern area, downstream of the Sør-Rondane Mountains, bare icefields exist only near nunataks and on the downstream side of the prevailing wind direction. Sites N1, N2 and N3 are located near one of the nunataks called Romnoesfjellet (Fig. 1). These sites were included to investigate the variation of fabric with distance from the nunatak. They are roughly on the same contour line and the distance from each sampling site to the nunatak is 7.5 , 4.5 and $1.5 \mathrm{~km}$, respectively. Schematic flowlines around the mountains, drawn perpendicular to the contour lines, are shown in Figure 1.

In the bare icefields, many cracks penetrate the ice sheet from the surface. Since cracks are formed due to tensile strain, inspection of cracks penetrating the ice was also carried out to investigate the stress/strain configuration at the sites. The cracks are observed as sharp white lines running in various directions on the bare-ice surface. In some places, they form parallel lines. In other places, they criss-cross randomly. Distances between one clear crack and its neighbour vary from a few centimeters to about $20 \mathrm{~cm}$. Crack density decreases with depth. Observation of the $15 \mathrm{~m}$ ice core collected at $\mathrm{E} 1$ reveals several cracks at $5 \mathrm{~m}$ depth but few at $10 \mathrm{~m}$ depth.

\section{OBSERVATION RESULTS}

For locations E1-E4, each ice sample exhibited a similar fabric pattern - a single-maximum pattern with its major axis roughly on the horizontal plane. Figure 2 shows the observed ice-fabric patterns. In Figure 2, the ice fabrics are projected on to the lower hemisphere of a Schmidt equal-area projection. The geographical orientation is denoted by "N" (north) and "S" (south). The direction of the maximum surface slope measured at each sampling site is denoted by " $\mathrm{M}$ ". The orientation of the $c$-axis of each crystal grain is projected as a dot. The disposition of cracks in the ice are drawn as dashed curves in each diagram. When the crack plane in the ice is projected on to the Schmidt net, it is represented by a curve. Each curve indicates the orientation of the horizontal section of the crack plane which is exposed in the bare-ice surface. The curvature indicates the inclination of the plane. As the inclination of the plane steepens, the curve straightens.

Each fabric diagram exhibits similar features. The axis of the single maximum evident in each fabric diagram deviates anticlockwise by $60^{\circ} \sim 90^{\circ}$ from the direction of the maximum surface slope at E1, E2 and E3, but clockwise at E4. The direction of the deviation is always towards the side where the nearest nunatak is, sites E1, E2 and $\mathrm{E} 3$ being on the eastern side of the mountains and $\mathrm{E} 4$ in the drainage west of Austhamaren (Fig. 1). In addition, the axis of the single maximum inclines downward in that direction. Moreover, each diagram can be considered as a double-maxima fabric, E1, E2 and E3 exhibiting a weak second maximum, although it is not very clear at $\mathrm{E} 4$. The weak second maxima are always between the major axis and the direction of the maximum surface slope. These similar features of the fabric data from different sites suggest that each ice sample has been subjected to a similar stress/strain configuration.

For site E1, no significant difference was found between the ice fabric at $0.5 \mathrm{~m}$ depth and those at 5.2 and $11.5 \mathrm{~m}$ (Fig. 2). In other bare icefields in the Antarctic ice sheet, it has also been reported that there is no significant difference in crystal structure between the surface ice and $10 \mathrm{~m}$ deep ice (Nishio and others, 1982; Azuma and others, 1985). Thus, neither solar heat, stress around the micro-cracks nor the seasonal variation of the ice temperature is thought to change the fabrics in surface ice compared with deeper ice, at least at the site E1. Considering that the annual mean temperature at Asuka Station (Fig. 1; $930 \mathrm{~m}$ a.s.l.) is $-18^{\circ} \mathrm{C}$, the annual mean temperatures at the sites are expected to be between approximately $-18^{\circ} \mathrm{C}$ and $-28^{\circ} \mathrm{C}$, depending on the elevation of the sites. Since, at such a low temperature, recrystallization is not a dominant factor in the formation of ice fabrics, in most cases crystal structure, even in the bare-ice surface, needs to be explained by the strain history.

Figure 3 shows the fabric pattern at sites N1, N2 and 


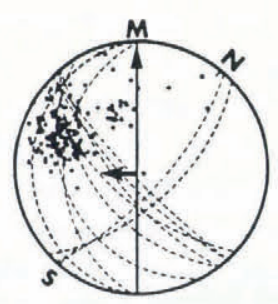

E1

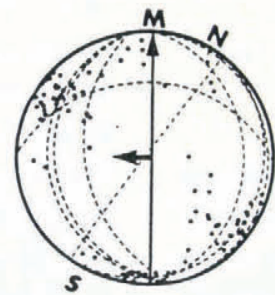

E2

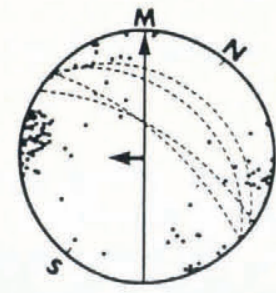

E3 $d=0.6 \mathrm{~m}$
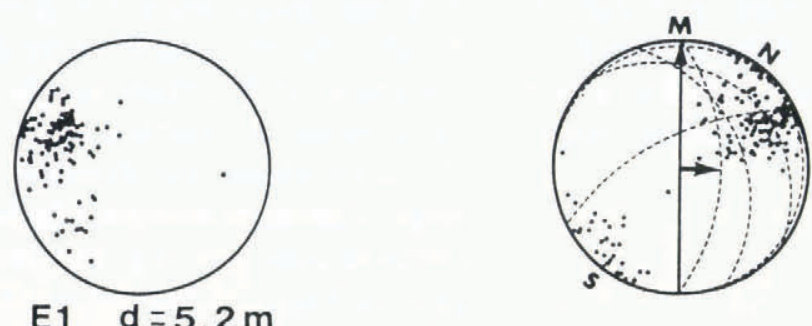

E4 $d=0.5 m$

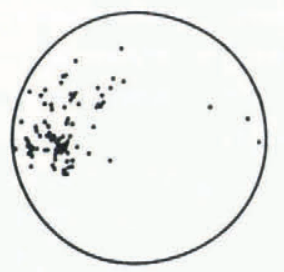

E1 $d=11.5 \mathrm{~m}$

Fig. 2. The fabric patterns and disposition of cracks in the ice surface at sites E1 (three depths), E2, E3 and E4, projected onto the lower hemisphere of the Schmidt equal-area projection. In the diagram, the orientations of the c-axes are projected as dots, and the dispositions of cracks are projected as dashed curves. The center of the diagram represents the vertical direction. " $M$ " denotes the direction of maximum surface slope surveyed near the sampling site. " $\mathcal{N}$ " and " $S$ " denote geographical north and south respectively. " $d$ "' is the depth of the sample. Short arrows denote the side to the nearest nunatak.

N3. The fabric pattern is almost random at N1. However, it gradually exhibits a strong single-maximum pattern at $\mathrm{N} 2$ and N3, on flowlines closer to the nunatak. This is similar to the trend found for E1, E2, E3 and E4. Near sites N1, N2 and N3, the ice sheet flows approximately from south-southwest to north-northeast, deduced from the direction of the maximum surface slope on the map in Figure 1. In Figure 3, the direction to the nunatak Romnoesfjellet is denoted by " $R$ ". We shall discuss the formation process of the observed fabric pattern below.

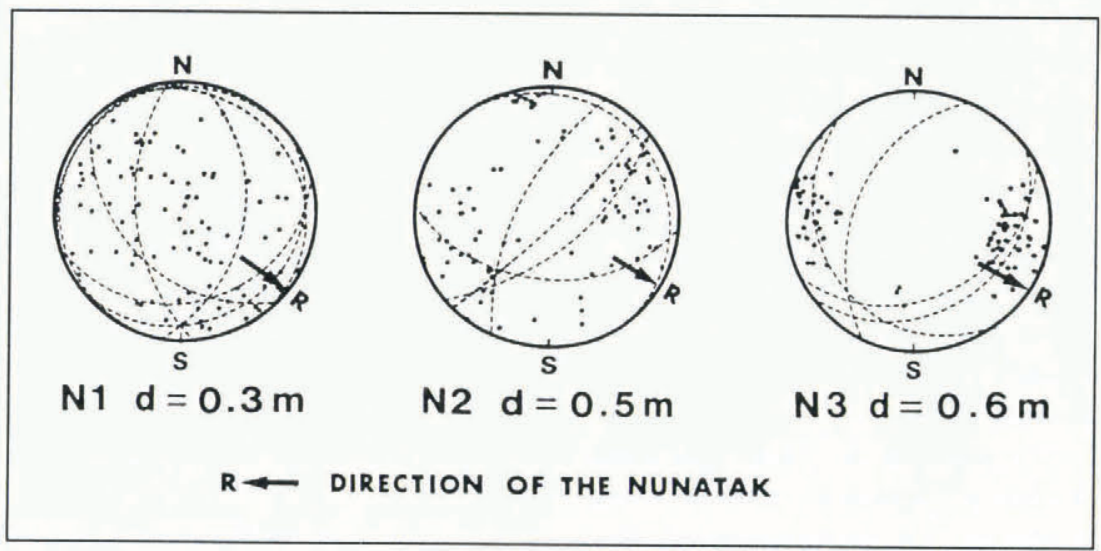

Fig. 3. The fabric patterns and disposition of cracks in the ice surface at sites $\mathcal{N} 1, \mathcal{N} 2$ and $\mathcal{N} 3$. The arrows with " $R$ " denote the direction of nunatak Romnoesfjellet. The distances from the sampling sites $\mathcal{N} 1, \mathcal{N} 2$ and $\mathcal{N} 3$ to the nunatak are $7.5,4.5$ and $1.5 \mathrm{~km}$, respectively. 


\section{DISCUSSION}

\section{Strain configuration in the ice sheet adjacent to the mountains}

We now discuss the formation process of the observed fabric and the configuration of the strain in the ice sheet adjacent to the mountains. The formation process of the observed single-maximum fabric patterns can be explained as the result of simple shear strain between the ice and the nunataks as denoted by arrows in Figure 4. Moreover, since fabric patterns from different sites have many similar features, it can be said that the ice surface adjacent to the mountains is widely subjected to vertical simple shear strain.

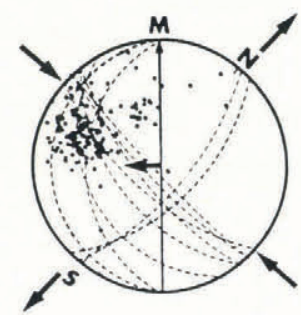

E1
$0.5 \mathrm{~m}$

a

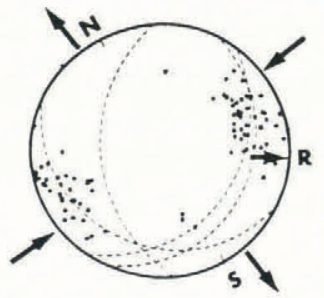

N3
$0.6 \mathrm{~m}$
Fig. 4. The principal axis of the cumulative simple shear strain deduced from the fabric data for sites E1 and N3.

In general, a single-maximum pattern in which the axis of the maximum is vertical develops in horizontal simple shear zones in polar ice sheets (e.g. Russell-Head and Budd, 1979). Moreover, in laboratory experiments, it has also been verified that a similar single-maximum pattern which sometimes has a weak second maximum is formed due to simple shear strain (e.g. Bouchez and Duval, 1982). It is proposed that the single-maximum fabrics found in this study, with the axis of the maximum perpendicular to the flowline, are formed by simple shear of the ice past the side wall of the nunataks. Similar patterns have been reported by Kizaki (1969) in the surface ice in a high-shear zone in the Mawson region.

Azuma and Higashi (1985) and Azuma (1986) have shown that a single-maximum fabric pattern is formed when polycrystalline ice is uniaxially compressed, due to the rotation of the $c$-axis of each grain towards the axis of compression. They proposed a model which described the relation between strain and development of the fabric quantitatively during uniaxial compression. It is also possible to interpret the fabric pattern observed here from this "ice-grain rotation model".

Fujita and others (1987) modified the model proposed by Azuma (1986) to examine the formation process of the fabric developed under tension, on the assumption that the model is applicable to tensile deformation. Moreover, Alley (1988) has discussed the formation process of the fabric developed under shear deformation which is a combination of compression and tension. He suggested that, if ice initially exhibiting an isotropic fabric is subjected to simple shear, a single-maximum fabric develops in the compressive principal axis of the shear strain, i.e. at $45^{\circ}$ to the shear plane. It was also suggested that, as strain increases, the axis of the single maximum begins to deviate towards the direction perpendicular to the shear plane due to rigid-body rotation of the system.

If this idea is applied to the case of the fabrics observed in this study, the compressive principal axis is in the direction away from the downward direction of the flowline by $45^{\circ}$ anticlockwise for E1, E2 and E3, and clockwise for E4. Here, simple shear is assumed to exist between the ice flow and the nunataks. Based on the idea described above, the direction in which the axis of the single maximum is formed deviates towards the direction perpendicular to the flowline from the compressive principal axis of shear strain. This condition agrees well with the observed fabric pattern shown in Figure 2.

Examination of the disposition of observed crack planes in Figure 2 shows that some roughly correspond to the normal of the tensile principal axis of the deduced simple shear, while others do not. This fact suggests that cumulative strain in ice deduced from fabrics does not necessarily correspond to the surface strain rate at the sampling site. However, this geometrical interpretation is in good agreement with most of the observations, and gives a plausible explanation to the formation processes of the observed fabric patterns.

The development of the ice-fabric pattern under simple shear strain can be simulated, since the crystallographic characteristics under compression and tension have been given by Azuma and Higashi (1985) and Azuma (1986), and by Fujita and others (1987), respectively. Simple calculations show that the axis of the single maximum deviates from the compressive principal axis towards the direction perpendicular to the shear

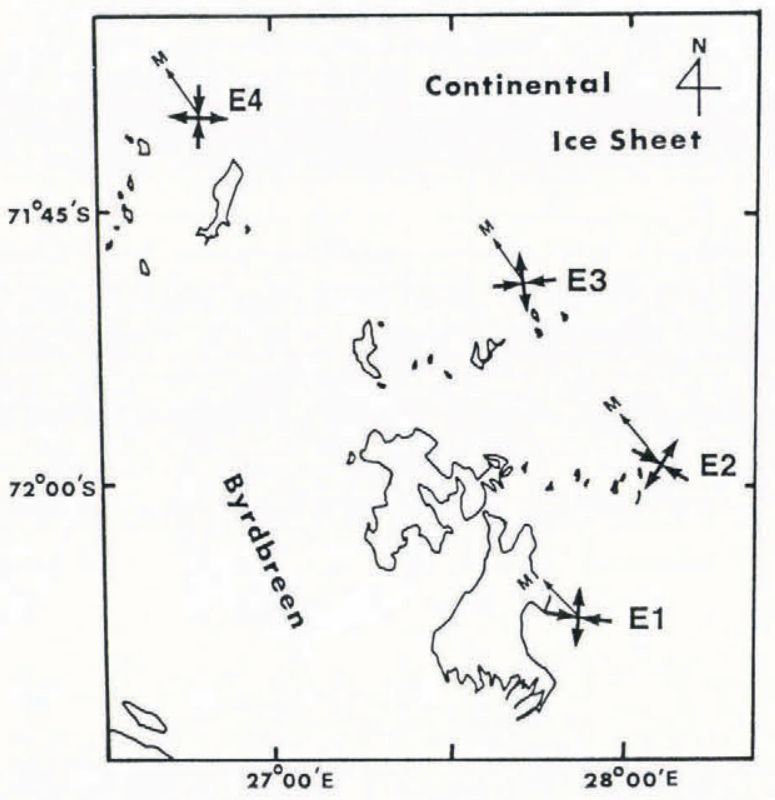

Fig. 5. The configuration of surface strain deduced from the fabric data (short arrows), and direction of maximum surface slope surveyed near sites E1, E2, E3 and E4 (long arrows with " $M$ "). 
plane due to the rigid-body rotation of the system. The deviation approaches $45^{\circ}$ for infinite strain. Comparing the simulated fabric pattern with the observed fabric pattern, the cumulative effective shear strain was deduced. It was about 1.0, 0.9, 0.5 and 1.0 for E1, E2, E3 and E4, respectively. In this case, the compressive principal axis of the shear strain is in the direction away from the axis of the single maximum by about $25^{\circ}, 24^{\circ}$, $19^{\circ}$ and $25^{\circ}$, respectively. The directions of the stress/ strain configuration in the ice sheet deduced in this way are shown in Figure 4a and Figure 5.

\section{Distance from the nunatak and strain}

The formation process of the fabric pattern collected at N1, N2 and N3 can be explained by the same mechanism as discussed in the previous section. That is, the ice west of Romnoesfjellet is subjected to shear strain between the nunatak and the ice flow. As in Figure 3, the closer the site is to the nunatak, the stronger is the developed singlemaximum fabric. It is deduced from this that cumulative shear strain in the ice is greater nearer to the nunatak. In this case, the deduced cumulative shear strain is about 0 , 0.4 and 1.1 for N1, N2 and N3, respectively. The compressive principal axis of the shear strain is in the direction away from the axis of the single maximum by about $15^{\circ}$ and $27^{\circ}$ for N2 and N3, respectively. An example of the stress/strain configuration deduced in this way is shown in Figure $4 b$.

\section{ACKNOWLEDGEMENTS}

The authors wish to thank Dr K. Yanai of the National Institute of Polar Research, Dr H. Naraoka of Tohoku University, and members of the JARE-29 Asuka-party for their support of these investigations.

\section{REFERENCES}

Alley, R.B. 1988. Fabrics in polar ice sheets: development and prediction. Science, 240(4851), 493-495.

Azuma, N. 1986. Experimental studies on the development of texture and flow behaviour of ice in polar ice sheets. (Ph.D. thesis, Hokkaido University.) [In Japanese.]

Azuma, N. and A. Higashi. 1985. Formation processes of ice fabric pattern in ice sheets. Ann. Glaciol., 6, 130-134.

Azuma, N. and S. Mae. 1988. The effect of c-axis orientation fabric on the flow rate of ice; derivation from in situ observation of deformation behavior of individual grain. In Saeki, H. and K. -i. Hirayama, eds. Proceedings, the 9th International Symposium on Ice, 23-27 August 1988, Sapporo, Japan. Vol. 1. Delft, International Association for Hydraulic Research. Committee on Ice Problems, 67-76.

Azuma, N., M. Nakawo, A. Higashi and F. Nishio. 1985. Flow pattern near Massif $\mathrm{A}$ in the Yamato bare ice field estimated from the structures and the mechanical properties of a shallow ice core. Mem. Natl. Inst. Polar Res., Spec. Issue 39, 173-183.

Bouchez, J.L. and P. Duval. 1982. The fabric of polycrystalline ice deformed in simple shear: experiments in torsion, natural deformation and geometrical interpretation. Textures and Microstructures, 5, 171-190.

Fujita, S., M. Nakawo and S. Mae. 1987. Orientation of the 700-m Mizuho core and its strain history. Proceedings of the NIPR Symposium on Polar Meteorology and Glaciology 1, 122-131.

Jacka, T.H. and W.F. Budd. 1989. Isotropic and anisotropic flow relations for ice dynamics. Ann. Glaciol., 12, 81-84.

Kizaki, K. 1969. Ice-fabric study in the Mawson region, East Antarctica. F. Glaciol., 8(53), 253-276.

Naraoka, H., K. Yanai and S. Fujita. 1990. Report on Antarctic meteorites search around the Sør-Rondane Mountains, JARE-29 1988-1989. Antarctic Record, 34(2), 216-224. [In Japanese.]

Nishio, F., N. Azuma, A. Higashi and J. O. Annexstad. 1982. Structural studies of bare ice near the Allan Hills, Victoria Land, Antarctica: a mechanism of meteorite concentration. Ann. Glaciol., 3, 222-226.

Russell-Head, D. S. and W.F. Budd. 1979. Ice-sheet flow properties derived from bore-hole shear measurements combined with ice-core studies. F. Glaciol., 24(90), 117-130.

Shoji, H. and C. C. Langway, Jr. 1988. Flow-law parameters of the Dye 3, Greenland, deep ice core. Ann. Glaciol., 10, 146-150.

The accuracy of references in the text and in this list is the responsibility of the authors, to whom queries should be addressed. 